\title{
Association between the BRCA2 N372H variant and male breast cancer risk: a population-based case-control study in Tuscany, Central Italy
}

\author{
Domenico Palli ${ }^{1}$, Mario Falchetti ${ }^{2}$, Giovanna Masala ${ }^{1}$, Ramona Lupi ${ }^{2}$, \\ Francesco Sera ${ }^{1}$, Calogero Saieva ${ }^{1}$, Cristina D'Amico ${ }^{2}$, Marco Ceroti ${ }^{1}$, \\ Piera Rizzolo ${ }^{2}$, Maria Adelaide Caligo ${ }^{3}$, Ines Zanna ${ }^{1}$ and Laura Ottini*2
}

\begin{abstract}
Address: ${ }^{1}$ Molecular and Nutritional Epidemiology Unit, CSPO, Scientific Institute of Tuscany, 50139 Florence, Italy, ${ }^{2}$ Department of Experimental Medicine, University of Rome "La Sapienza", 00161 Rome, Italy and ${ }^{3}$ Division of Surgical, Molecular and Ultrastructural Pathology, Department of Oncology, University of Pisa and Pisa University Hospital, 56126 Pisa, Italy

Email: Domenico Palli - d.palli@cspo.it; Mario Falchetti - mario.falchetti@uniroma1.it; Giovanna Masala - g.masala@cspo.it;

Ramona Lupi - ramona.lupi@uniroma1.it; Francesco Sera - f.sera@cspo.it; Calogero Saieva - c.saieva@cspo.it;

Cristina D'Amico - cdamico@supereva.it; Marco Ceroti - m.ceroti@cspo.it; Piera Rizzolo - pierarizzolo@yahoo.it;

Maria Adelaide Caligo - m.caligo@med.unipi.it; Ines Zanna - i.zanna@cspo.it; Laura Ottini* - laura.ottini@uniroma1.it

* Corresponding author
\end{abstract}

Published: 3 September 2007

BMC Cancer 2007, 7:170 doi:10.1 I86/147/-2407-7-170
Received: 23 January 2007

Accepted: 3 September 2007

This article is available from: http://www.biomedcentral.com/147/-2407/7//70

(c) 2007 Palli et al; licensee BioMed Central Ltd.

This is an Open Access article distributed under the terms of the Creative Commons Attribution License (http://creativecommons.org/licenses/by/2.0), which permits unrestricted use, distribution, and reproduction in any medium, provided the original work is properly cited.

\begin{abstract}
Background: Male breast cancer (MBC) is a rare disease and little is known about its aetiology. Germline mutations of $B R C A 2$ and, at lower frequency, of $B R C A I$ are implicated in a relatively small proportion of $M B C$ cases. Common polymorphic variants in BRCAI and BRCA2 genes may represent breast cancer (BC) susceptibility alleles and could be associated with a modestly increased risk of $M B C$ at population level. Considering the relevant role of $B R C A 2$ in MBC, we investigated whether the BRCA2 N372H variant, representing the only common non-synonymous polymorphism in BRCA2, might modulate the risk of $B C$ in male populations.

Methods: A case-control study was performed comparing a population-based series of $99 \mathrm{MBC}$ cases, characterized for BRCAI and BRCA2 mutations, with 261 male population controls, all residing in Tuscany, Central Italy. All MBC cases and controls were genotyped for the BRCA2 N372H allele by TaqMan allelic discrimination assays. To evaluate the genotype specific risk of the $B R C A 2 \mathrm{~N} 372 \mathrm{H}$ variant, MBC carriers of germ-line BRCA / /2 mutations were excluded from the analyses.

Results: No association emerged in univariate and age-adjusted analyses. Age-specific analyses suggested an increased risk for the $\mathrm{HH}$ homozygous genotype in subjects younger than 60 years. A statistically significant interaction emerged between this genotype and age $(p=0.032)$. When analyses were restricted to $M B C$ cases enrolled in the first 4 years following diagnosis, a recessive model showed a significantly increased risk of $\mathrm{MBC}$ in $\mathrm{HH}$ subjects younger than 60 years $(\mathrm{OR}=5.63 ; 95 \% \mathrm{Cl}=1.70 ; 18.6 \mathrm{I})$.

Conclusion: Overall, our findings, although based on a relatively small series, suggest that the BRCA2 HH homozygous genotype might be positively associated with an increased risk of MBC in men younger than 60 years.
\end{abstract}




\section{Background}

Male breast cancer (MBC) is a rare disease and little is known about its aetiology compared with female breast cancer (FBC). MBC represents less than $1 \%$ of all cancers in men and its incidence is increasing in younger men [1]. In Italy, MBC accounts for $0.2 \%$ of all cancers in males [2].

Similar to FBC, a positive family history (FH) of breast cancer (BC) is associated with increased risk of $\mathrm{MBC}$ and approximately $15 \%$ to $20 \%$ of male patients with $\mathrm{BC}$ have a positive $\mathrm{FH} \mathrm{[3].} \mathrm{The} \mathrm{two} \mathrm{major} \mathrm{hereditary} \mathrm{BC}$ genes, BRCA1 (OMIM \#113705) and, to a larger extent, BRCA2 (OMIM \# 600185), are implicated in MBC. Both genes are estimated to be responsible respectively for up to $16 \%$ and $76 \%$ of the MBCs in high-risk breast/ovarian cancer families $[3,4]$. The frequencies of BRCA1/BRCA2 mutations are sharply different in ethnically diverse population- and clinic-based series ranging from $0 \%$ to $4 \%$ for BRCA 1 and from $4 \%$ to $40 \%$ for BRCA2 [5,6]. However, at population level only a small proportion of all MBC cases are due to inherited mutations in BRCA1/BRCA2 genes.

Low-penetrance polymorphisms in BC susceptibility genes are present in a high percentage of individuals and might account for $\mathrm{BC}$ risk at population level. In this respect, common polymorphic variants in BRCA1/BRCA2 genes may represent $\mathrm{BC}$ susceptibility alleles and could be associated with a modest risk of MBC that would explain, on population basis, a large proportion of the disease.

The N372H (rs144848) polymorphism is the unique variant in BRCA2 gene that results in an amino acid change and has a rare allele frequency greater than $10 \%$. Little is known on the functional effect of this polymorphism, although the substitution of asparagine (a neutral amino acid) by histidine (a basic amino acid) may be expected to affect BRCA2 structure and function as it falls in a region that has been shown to interact with the histone acetyltransferase $\mathrm{P} / \mathrm{CAF}$ prior to transcriptional activation of other genes [7]. Intriguingly, an excess of NH heterozygotes was observed in female controls and an effect of this variant on fetal survival in a sex-dependent manner has been suggested as newborn females showed an excess of heterozygotes and a deficit of homozygotes, whereas the opposite was observed in newborn males [8].

Several studies have analysed the effect of the BRCA2 N372Hpolymorphism on the risk of breast cancer in female populations with inconsistent findings. The $\mathrm{HH}$ homozygous genotype was reported to be associated with a 1.3- to 1.5-fold increased risk of breast and ovarian cancer [8-11]. In contrast, other studies did not show any effect of this polymorphism on breast or ovarian cancer risk [12-15]. A recent large pooled analysis, however, could not exclude an effect of this genotype in younger women [16]. To our knowledge, the effect of the BRCA2 $\mathrm{N} 372 \mathrm{H}$ polymorphism on BC risk has not yet been investigated in male populations.

Considering the relevance of $B R C A 2$ in $\mathrm{MBC}$, we have performed a population-based case-control study to investigate the role of $B R C A 2 \mathrm{~N} 372 \mathrm{H}$ variant on $\mathrm{BC}$ risk in men, comparing a series of $\mathrm{MBC}$, characterized for BRCA1 and $B R C A 2$ mutation status, with a control group from the same area of Central Italy (Florence, Tuscany).

\section{Methods}

\section{Study population and data collection}

In a previous study [17], we had identified a populationbased series of $25 \mathrm{MBC}$ cases diagnosed in the area of Florence (Tuscany, Central Italy) during the period 19901998. One of the problems in MBC studies is represented by the rarity of the disease: in order to increase the number of cases for meaningful statistical analyses it is necessary to enrol patients diagnosed over a long period of time (or in a larger geographical area). Thus, using all available local sources (including Pathology Departments and the Hospital Discharge database) the original series has been expanded and 74 additional MBC cases diagnosed in the period 1991-2006 have been enrolled for a total of 99 MBCs available for this study, all residing in Tuscany.

Overall, after exclusion of deceased and migrated patients, 85 additional unrelated MBC were traced and invited to participate into the study. Eleven cases refused to participate, mostly because of advanced age or severe illness. Confirming our previous response rate of about $80 \%, 74$ of these $85 \mathrm{MBC}$ cases $(87.1 \%)$ agreed to participate. According to the original study protocol, each $\mathrm{MBC}$ patient provided: 1) informed consent; 2) blood samples; 3) detailed information on his personal and family history of cancer at any site, including all first- and seconddegree relatives of both genders; 4) a detailed smoking and working history up to the date of BC diagnosis. Information has been validated by available sources (mainly local Cancer and Mortality Registries). Procedures to maintain confidentiality for all the information collected have been developed and strictly applied. The study was approved by the local Ethical Research Committee (Florence Health Unit).

\section{Population controls}

In the frame of a multi-site epidemiological project, two series of healthy adults of both sexes have been randomly selected from the municipality lists of two areas in Tuscany: the city of Florence and one rural area [18,19]. All participants signed an informed consent form and provided a blood sample. Out of 700 randomly selected subjects, 553 subjects (79\%) accepted to participate into the 
study; males were 48.6\% (269/553) and 261 samples were available for analyses (eight of the initial 269 control's samples ( $3 \%$ ) yielded insufficient DNA). The blood samples have been processed at the study laboratory (CSPO, Florence), in the same day of collection and divided in specific aliquots (RBC, buffy coat, serum, plasma). The aliquots have been stored in a $-80^{\circ} \mathrm{C}$ freezer at the Biological Bank of the Molecular Epidemiology Unit at CSPO.

\section{Mutational analysis}

Buffy coat aliquots from MBC cases and controls were anonymously shipped to the research laboratory (Experimental Medicine, Rome) where genomic DNA was extracted using QIAamp DNA Mini Kit (Qiagen Inc., Charlesworth, CA). The entire BRCA1 and BRCA2 coding sequences, including intron-exon boundaries, were analysed by using single strand conformation polymorphisms (SSCP) combined with protein truncation test (PTT) and automatic sequencing analysis $[17,20]$. Mutations were always verified by PCR direct sequencing on two independent blood samples (reference sequence for BRCA1: Genbank, U14680; reference sequence for BRCA2: Genbank, NM_000059).

\section{SNP genotyping}

The BRCA2 N372H (rs144848) polymorphism was analysed by TaqMan allelic discrimination using Real-Time PCR. Fluorescent hybridisation probes, labelled with 6carboxyfluorescin (FAM) to detect the 1342C (372H) allele and with Texas Red to detect the 1342A (372N) allele were specifically designed. TaqMan assays were performed in a reaction volume of $50 \mu \mathrm{l}$, comprising $100 \mathrm{ng}$ of DNA, $400 \mathrm{nM}$ each probe, $400 \mathrm{nM}$ each primer and $1 \times$ Universal Master Mix (Biorad). The following conditions were used for amplification: 3 minutes at $95^{\circ} \mathrm{C}$ and 55 cycles at $95^{\circ} \mathrm{C}$ for $10^{\prime \prime}$ and $63^{\circ} \mathrm{C}$ for $45^{\prime \prime}$. The Real-Time PCR was accomplished on iCycler thermal cycler (Biorad) with $96 \times 0.2 \mathrm{ml}$ samples. The fluorescence was visualised through iCycler Optical System (Biorad) during RealTime PCR and analysed by using the iCycler IQ Real-Time Detection System (Biorad) 3.0 software. About 15\% of the genotyping results were confirmed by sequencing analysis. The genotype controls for the three possible genotypes plus "no template" controls were always included in each analysis.

\section{Statistical analysis}

Allele frequencies have been calculated as the number of alleles divided by the number of chromosomes. Genotype frequencies have been calculated as the number of participants with a particular genotype divided by the number of participants. Tests for Hardy-Weinberg equilibrium among cases and controls have been assessed using Pearson's $\chi^{2}$ test with one degree of freedom comparing expected genotype frequencies (based on observed qs) to observed genotype frequencies. The association between $\mathrm{MBC}$ risk and BRCA2 N372H was measured by the odds ratio (OR) and its corresponding 95\% confidence interval and was estimated using unconditional logistic regression after adjustment for age considered as dichotomous variable ( $<60$ years, $>60$ years). The analysis were performed with four logistic regression models based on a co-dominant, dominant, recessive and multiplicative codominant effect (inheritance model). In the dominant model, both the heterozygous variant and rare homozygous variant were combined in a dummy variable. In the recessive model, the variant was defined in a dummy variable as only the rare homozygous genotype. In the co-dominant model both rare homozygous and heterozygous variant effects were estimated using two dummy variables while in the multiplicative codominant model a dose-response effect were tested on the variable counting the number of copies of the $\mathrm{H}$ allele. Analyses have also been carried out according to stratification by age at diagnosis for cases and age at interview for controls (below/above 60 years) and restricted to $\mathrm{MBC}$ cases with a time interval after diagnosis shorter than the median value of the series (4 years). Interactions between age, modelled as dichotomous variable (<60 years, >60 years), and genotype under co-dominant, dominant, recessive and multiplicative codominant models, were assessed using Likelihood Ratio test (LR) comparing logistic regression models with and without interaction term.

\section{Results}

In order to evaluate the putative influence of the BRCA2 $\mathrm{N} 372 \mathrm{H}$ polymorphism on MBC risk, we carried out a population-based case-control study based on a total of 99 MBC cases and 261 adult male controls from the same area of Central Italy (Florence, Tuscany). The mean age at interview was 67.9 (SD 11.8) in cases and 55.9 (SD 6.9) in controls $(\mathrm{p}<0.0001)$. The mean age at diagnosis in the MBC series was 63.4 (SD 12.1; median 65) and the time interval between diagnosis and interview ranged from 0 to 26 years (median 4.0). A detailed FH for breast and ovarian cancers diagnosed in first-degree relatives was collected for all MBC cases. Overall, 25.3\% (25/99) of MBC patients reported a first degree $\mathrm{FH}$ positive for breast/ovarian cancer.

MBC cases were characterized for BRCA1 and BRCA2 mutations. Overall, 8/99 (8.1\%) MBC cases resulted to be mutated in BRCA1/BRCA2 genes: 6 cases $(6.1 \%)$ carried BRCA2 mutations and 2 cases $(2.0 \%)$ carried BRCA1 mutations. All $99 \mathrm{MBC}$ cases and 261 controls were analysed for the BRCA2 N372H allele and genotype frequencies. Genotype distribution was consistent with HardyWeinberg equilibrium $(\mathrm{p}=0.529)$ among our population controls and cases $(p=0.067)$. In order to evaluate the 
genotype specific risk of the BRCA2 N372H polymorphism, MBC carriers of germ-line BRCA1/2 mutations ( 8 cases) were excluded from the analyses.

As shown in Table 1, no statistically significant difference in the distribution of the three specific BRCA2 N372H genotypes was observed between $\mathrm{MBC}$ cases and controls $(\mathrm{p}=0.46)$. The age-adjusted analysis of the genotype-specific risks showed that individuals with $\mathrm{NH}$ heterozygous and $\mathrm{HH}$ homozygous genotypes were not at increased MBC risk. These results were confirmed on dominant, recessive and multiplicative codominant transmission models (data not shown). Separate analyses stratified according to age (below/above 60 years) showed a tendency towards an inverse association between the $\mathrm{H}$ allele and $\mathrm{MBC}$ risk in the older sub-group (age > 60 years), although far from being statistically significant. On the contrary, an increased $\mathrm{MBC}$ risk $(\mathrm{OR}=3.12 ; 95 \% \mathrm{CI}=$ $1.08 ; 9.03$ ) was observed in younger subjects (age $\leq 60$ years) on the basis of a recessive model (Table 2). A model specifically aimed to evaluate a possible effect modification of age on the association between $\mathrm{MBC}$ risk and the HH homozygous genotype found a statistically significant interaction (LR test $\mathrm{p}=0.02 ; \mathrm{OR}_{\text {interaction }}=0.17 ; 95 \% \mathrm{CI}=$ $0.04 ; 0.76)$.

We carried out additional analyses taking into account the length of the interval between diagnosis and blood donation among cases. Overall, no association between the $\mathrm{H}$ allele and $\mathrm{MBC}$ risk was observed, when analyses were restricted to a comparison between the group of $53 \mathrm{MBC}$ cases with an interval shorter than the median value of the whole series ( $\leq 4$ years) and the series of controls (Table 3 ). Additional analyses stratified by age, showed a strongly increased $\mathrm{MBC}$ risk $(\mathrm{OR}=5.63 ; 95 \% \mathrm{CI}=1.70$; 18.61 ) in younger subjects with the HH homozygous genotype (Table 4), while no statistically significant result emerged in older individuals. Further statistical analyses confirmed that the effect of the HH homozygous genotype on MBC risk tended to be modified by age also in these analyses restricted to MBC cases with a shorter time interval between diagnosis and blood donation (LR test $\mathrm{p}$ $=0.03 ; \mathrm{OR}_{\text {interaction }}=0.17(95 \% \mathrm{CI}=0.04-0.83)$. Sensitivity analyses were carried out based on cut-off points for both age at diagnosis and time interval after diagnosis different from those identified $a$ priori. These analyses confirmed the association, when older individuals (up to 65 years of age) or cases with a longer time interval (up to 6 years) were included.

\section{Discussion}

We evaluated the effect of the BRCA2 N372H $(1342 \mathrm{~A}>\mathrm{C})$ polymorphism on $\mathrm{MBC}$ risk in a population based casecontrol study. Overall, a positive association between the $\mathrm{HH}$ genotype and an increased risk of $\mathrm{MBC}$ was suggested in men younger than 60 years; this association was particularly strong (with a five-fold increased risk) when analyses were restricted to $53 \mathrm{MBC}$ cases enrolled in the study with a blood donation not later than 4 years after their diagnosis. To our knowledge, the present study is the first reporting an analysis of the association between $\mathrm{BC}$ risk and the BRCA2 N372H variant in men.

The role of the BRCA2 N372H variant on $\mathrm{BC}$ risk has been investigated by several studies in women from different populations with inconsistent findings that might reflect genetic differences across populations. In particular the $\mathrm{HH}$ genotype was associated with a 1.3- to 1.5-fold increased risk of BC in series from Northern Europe [8], Australia [9] and in a selected series of radiologic technologists from USA [10]. This association was not detected in series from Central Europe [13], Japan [12] and in an unselected series from USA [14].

Here, we performed a population-based case control study on male subjects all residing in the same area of Central Italy (Tuscany). Our analyses based on a recessive transmission model suggested an association between the $B R C A 2 \mathrm{~N} 372 \mathrm{H}$ variant and increased MBC risk in men younger than 60 years. This effect on MBC risk was particularly evident when analyses were restricted to the subgroup of MBC cases with an interval between diagnosis and blood donation $\leq 4$ years, in order to avoid a possible selection bias related to the enrolment of MBC cases with a longer survival in the attempt of expanding the series of patients affected with this rare disease. Overall, we had found a statistically significant interaction between $\mathrm{N} 372 \mathrm{H}$ genotype and age: the effect on MBC risk of the

Table I: Distribution of 91 MBC cases not mutated in BRCA genes and 261 male population controls according to the BRCA2 N372H genotype frequencies.

\begin{tabular}{cccccc}
\hline Genotype & Cases $n$ & $\%$ & Controls $\mathrm{n}$ & $\%$ & Co-dominant model OR 95\% Cl \\
\hline $\mathrm{N} / \mathrm{N}$ & 48 & 52.7 & 127 & 48.7 & $0.68(0.40 ; 1.18)$ \\
$\mathrm{N} / \mathrm{H}$ & 31 & 34.1 & 107 & 41.0 & $0.94(0.43 ; 2.09)$ \\
$\mathrm{H} / \mathrm{H}$ & 12 & 13.2 & 27 & 10.3 & 100.0 \\
Total & 91 & 100.0 & 261 &
\end{tabular}

Odds Ratios (OR) and $95 \%$ Confidence Intervals according to a co-dominant model, estimated by a logistic regression model after adjustment for age considered as a dichotomous variable ( $<60$ years, $>60$ years). 
Table 2: Distribution of 91 MBC cases not mutated in BRCA genes and 261 male population controls according to the BRCA2 N372H genotype frequencies, stratified by age at diagnosis.

\begin{tabular}{|c|c|c|c|c|c|c|}
\hline Genotype & Cases $\mathrm{n}$ & $\%$ & Controls n & $\%$ & $\begin{array}{c}\text { Co-dominant } \\
\text { model OR } 95 \% \mathrm{Cl}\end{array}$ & $\begin{array}{c}\text { Recessive model } \\
\text { OR } 95 \% \mathrm{Cl}\end{array}$ \\
\hline \multicolumn{7}{|l|}{$\leq 60$ years } \\
\hline $\mathrm{N} / \mathrm{N}$ & 16 & 50.0 & 94 & 54.0 & & \\
\hline $\mathrm{N} / \mathrm{H}$ & 10 & 31.2 & 68 & 39.1 & $0.86(0.37 ; 2.03)$ & \\
\hline $\mathrm{H} / \mathrm{H}$ & 6 & 18.8 & 12 & 6.9 & $2.94(0.94 ; 9.15)$ & $3.12(1.06 ; 9.16)$ \\
\hline Total & 32 & 100.0 & 174 & 100.0 & & \\
\hline \multicolumn{7}{|l|}{$>60$ years } \\
\hline $\mathrm{N} / \mathrm{N}$ & 32 & 54.2 & 33 & 37.9 & & \\
\hline $\mathrm{N} / \mathrm{H}$ & 21 & 35.6 & 39 & 44.8 & $0.56(0.27 ; 1.15)$ & \\
\hline $\mathrm{H} / \mathrm{H}$ & 6 & 10.2 & 15 & 17.2 & $0.4 I(0.14 ; 1.22)$ & $0.54(0.20 ; 1.5 \mathrm{I})$ \\
\hline Total & 59 & 100.0 & 87 & 100.0 & & \\
\hline
\end{tabular}

Odds Ratios (OR) and 95\% Confidence Intervals according to co-dominant and recessive models, estimated using logistic regression models. Interaction among between BRCA2 N372H genotype and age: $\mathrm{OR}_{\text {interaction }}=0.17(95 \% \mathrm{Cl}=0.04-0.76) ; \mathrm{p}=0.02$.

Table 3: Distribution of $53 \mathrm{MBC}$ cases with a time interval between diagnosis and interview $\leq 4$ years and $26 \mathrm{I}$ male population controls according to the BRCA2 N372H genotype frequencies.

\begin{tabular}{cccccc}
\hline Genotype & Cases $n$ & $\%$ & Controls $n$ & $\begin{array}{c}\text { Co-dominant model } \\
\text { OR 95\% Cl }\end{array}$ & $\begin{array}{c}\text { \% } \\
\text { N/N }\end{array}$ \\
N/H & 24 & 45.2 & 127 & 48.7 & $0.79(0.40 ; 1.58)$ \\
H/H & 18 & 34.0 & 107 & 41.0 & $1.67(0.70 ; 3.97)$ \\
Total & 11 & 20.8 & 27 & 100.0 &
\end{tabular}

Odds Ratios (OR) and $95 \%$ Confidence Intervals according to a co-dominant model, estimated using logistic regression models after adjustment for age considered as a dichotomous variable ( $<60$ years, $>60$ years).

Table 4: Distribution of 53 MBC with a time interval between diagnosis and interview $\leq 4$ years and $26 \mathrm{I}$ male population controls according to the BRCA2 N372H genotype frequencies, stratified by age at diagnosis.

\begin{tabular}{|c|c|c|c|c|c|c|}
\hline Genotype & Cases $\mathrm{n}$ & $\%$ & Controls $n$ & $\%$ & $\begin{array}{c}\text { Co-dominant } \\
\text { model OR } 95 \% \mathrm{Cl}\end{array}$ & $\begin{array}{l}\text { Recessive model } \\
\text { OR } 95 \% \mathrm{Cl}\end{array}$ \\
\hline \multicolumn{7}{|l|}{$\leq 60$ years } \\
\hline $\mathrm{N} / \mathrm{N}$ & 6 & 35.3 & 94 & 54.0 & & \\
\hline $\mathrm{N} / \mathrm{H}$ & 6 & 35.3 & 68 & 39.1 & $1.38(0.43 ; 4.47)$ & \\
\hline $\mathrm{H} / \mathrm{H}$ & 5 & 29.4 & 12 & 6.9 & $6.53(1.73 ; 24.69)$ & $5.63(1.70 ; 18.61)$ \\
\hline Total & 17 & 100.0 & 174 & 100.0 & & \\
\hline \multicolumn{7}{|l|}{$>60$ years } \\
\hline $\mathrm{N} / \mathrm{N}^{\prime}$ & 18 & 50.0 & 33 & 37.9 & & \\
\hline $\mathrm{N} / \mathrm{H}$ & 12 & 33.3 & 39 & 44.8 & $0.56(0.24 ; 1.34)$ & \\
\hline $\mathrm{H} / \mathrm{H}$ & 6 & 16.7 & 15 & 17.2 & $0.73(0.24 ; 2.22)$ & $0.96(0.34 ; 2.7 I)$ \\
\hline Total & 36 & 100.0 & 87 & 100.0 & & \\
\hline
\end{tabular}

Odds Ratios (OR) and 95\% Confidence Intervals according to co-dominant and recessive models estimated using logistic regression models. Interaction between $\mathrm{BRCA} 2 \mathrm{~N} 372 \mathrm{H}$ genotype and age: $O R_{\text {interaction }}=0.17(95 \% \mathrm{Cl}=0.04-0.83) ; \mathrm{p}=0.03$.

HH homozygous genotype was significantly modified by age. In this respect, it is noteworthy that a recent pooled analysis with over 15,000 BC cases and 15,000 controls provided some evidence of an interaction of BRCA2 $\mathrm{N} 372 \mathrm{H}$ with age, suggesting a possibly increased BC risk in women younger than 40 years of age [16].
It could be speculated that the effect of the BRCA2 N372H variant on $\mathrm{BC}$ risk could be modulated by the interactions with hormonal factors. In males, the hormonal background is not influenced by reproductive factors as in females and sex steroid levels decline with age [21]. Intriguingly, an association of the BRCA2 N372H variant with idiopathic male infertility, a condition possibly 
related to increased sensitivity to estrogens, has been recently suggested [22]. Here, we found that the BRCA2 $\mathrm{N} 372 \mathrm{H}$ variant increased $\mathrm{MBC}$ risk in younger men that may show higher steroid hormones levels.

On the other hand, $\mathrm{MBC}$ risk could be influenced by interactions between genetic and environmental factors. Recently, we reported a possible modifying effect on MBC risk of an occupational exposure to chemicals, as polycyclic aromatic hydrocarbon, in subjects carrying BRCA1/2 germ-line mutations [23].

It has been also suggested that the BRCA2 N372H variant might affect fetal survival in a sex-dependent manner. In fact, an excess of $\mathrm{NH}$ heterozygotes in newborn females, compared to newborn males, has been observed and the BRCA2 N372H genotype distribution showed a significant deviation from the Hardy-Weinberg equilibrium in adult female controls with an excess of heterozygotes and a deficit of both homozygotes [8]. In our male population the overall distribution of the $\mathrm{N} 372 \mathrm{H}$ genotypes fitted the Hardy-Weinberg equilibrium and the genotype frequencies were similar to those recently reported for a male population from UK [24] and for female populations from Central Europe and USA $[13,14]$.

\section{Conclusion}

Overall, our findings, although based on a relatively small series, suggest that the HH homozygous genotype might be positively associated with an increased risk of MBC in men younger than 60 years. This effect appears to be modified by age, with a statistically significant interaction. Due to the rarity of $\mathrm{MBC}$, larger collaborative studies are needed to confirm our results in different male populations.

\section{Competing interests}

The author(s) declare that they have no competing interests.

\section{Authors' contributions}

DP participated in study design, coordination of field work, analysis and interpretation of data and critical review of the manuscript. MF performed SNP genotyping analyses and drafted the manuscript. GM and CS contributed to study design and statistical analyses. MC, MAC and IZ collected samples, clinical data and performed statistical analyses. RL, CDA, PR performed BRCA1 and BRCA2 mutational analysis. FS coordinated statistical analyses. LO participated in study design and supervision of experimental conduct and analysis, interpretation of results, drafting and revision of the manuscript, and approved the final version.

All authors read and approved the final manuscript.

\section{Acknowledgements}

The authors wish to thank all study participants for their availability, Prof. Simonetta Bianchi (Pathology Department, University of Florence), Dr.

Carmelo Urso and Dr. Federica Zolfanelli (Pathology Departments, ASL 10 Florence), Dr. Mauro Biancalani (Pathology Department, ASL II Empoli), Dr. Augusto Giannini (Pathology Department, ASL 4 Prato), Dr.s Francesco Mirri and Vincenzo Sforza (Pathology Departments, ASL 8 Arezzo) for their help with histologic confirmation, Dr Mariella Muraca (CSPO, Florence) and other local clinicians and general practitioners for their help in contacting patients. The study was carried out in the frame of the activities of the Cancer Family Program of Tuscany. The study was supported by a grant from Associazione Italiana per la Ricerca sul Cancro (AIRC) to Laura Ottini.

\section{References}

I. Perkins GH, Middleton LP: Breast cancer in men. BMJ 2003, 327:239-240.

2. Zanetti R, Gafà L, Pannelli F, Conti E, Rosso S, Ed: I dati di incidenza dei Registri Tumori. Volume terzo:1993-1998 Rome: II Pensiero Scientifico Editore; 200I.

3. Giordano SH, Buzdar AU, Hortobagyi GN: Breast cancer in men. Ann Intern Med 2002, 137:678-687.

4. Rahman N, Stratton MR: The genetics of breast cancer susceptibility. Annu Rev Genet 1998, 32:95-I2I.

5. Liede A, Narod SA: Hereditary breast and ovarian cancer in Asia: genetic epidemiology of BRCAI and BRCA2. Hum Mut 2002, 20:413-424.

6. Liede A, Karlan BY, Narod SA: Cancer risks for male carriers of germline mutations in BRCAI or BRCA2: a review of the literature. J Clin Oncol 2004, 22:735-742.

7. Fuks F, Milner J, Kouzarides T: BRCA2 associates with acetyltransferase activity when bound to P/CAF. Oncogene 1998, I 7:253I-2534.

8. Healey CS, Dunning AM, Teare MD, Chase D, Parker L, Burn J, Chang-Claude J, Mannermaa A, Kataja V, Huntsman DG, Pharoah PD, Luben RN, Easton DF, Ponder BA: A common variant in BRCA2 is associated with both breast cancer risk and prenatal viability. Nat Genet 2000, 26:362-364.

9. Spurdle AB, Hopper JL, Chen X, Dite GS, Cui J, McCredie MR, Giles GG, Ellis-Steinborner S, Venter DJ, Newman B, Southey MC, Chenevix-Trench G: The BRCA2 372 HH genotype is associated with risk of breast cancer in Australian women under age $\mathbf{6 0}$ years. Cancer Epidemiol Biomarkers Prev 2002, I I:413-4I6.

10. Sigurdson AJ, Hauptmann M, Chatterjee N, Alexander BH, Doody MM, Rutter JL, Struewing JP: Kin-cohort estimates for familial breast cancer risk in relation to variants in DNA base excision repair, BRCAI interacting and growth factor genes. BMC Cancer 2004, 4:9.

II. Auranen A, Spurdle AB, Chen X, Lipscombe J, Purdie DM, Hopper JL, Green A, Healey CS, Redman K, Dunning AM, Pharoah PD, Easton DF, Ponder BA, Chenevix-Trench G, Novik KL: BRCA2 Arg372 His polymorphism and epithelial ovarian cancer risk. Int J Cancer 2003, 103:427-430.

12. Ishitobi M, Miyoshi Y, Ando A, Hasegawa S, Egawa C, Tamaki Y, Monden M, Noguchi S: Association of BRCA2 polymorphism at codon 784 (Met/Val) with breast cancer risk and prognosis. Clin Cancer Res 2003, 9:1376-1380.

13. Menzel HJ, Sarmanova J, Soucek P, Berberich R, Grunewald K, Haun $M$, Kraft HG: Association of NQOI polymorphism with spontaneous breast cancer in two independent populations. $\mathrm{Br} J$ Cancer 2004, 90: 1989-1994.

14. Cox DG, Hankinson SE, Hunter DJ: No association between BRCA2 N372H and breast cancer risk. Cancer Epidemiol Biomarkers Prev 2005, 14:1353-1354.

15. Wenham RM, Schildkraut JM, McLean K, Calingaert B, Bentley RC, Marks J, Berchuck A: Polymorphisms in BRCAI and BRCA2 and risk of epithelial ovarian cancer. Clin Cancer Res 2003, 9:4396-4403.

16. Breast Cancer Association Consortium: Commonly studied single-nucleotide polymorphisms and breast cancer: results from the Breast Cancer Association Consortium. I Natl Cancer Inst 2006, 98: I 382-1 396.

17. Ottini L, Masala G, D'Amico C, Mancini B, Saieva C, Aceto G, Gestri D, Vezzosi V, Falchetti M, De Marco M, Paglierani M, Cama A, Bianchi 
S, Mariani-Costantini R, Palli D: BRCAI and BRCA2 mutation status and tumor characteristics in male breast cancer: a population-based study in Italy. Cancer Res 2003, 63:342-347.

18. Palli D, Saieva C, Luzzi I, Masala G, Topa S, Sera F, Gemma S, Zann I, D'Errico M, Zini E, Guidotti S, Valeri A, Fabbrucci P, Moretti R, Testai E, del Giudice G, Ottini L, Matullo G, Dogliotti E, GomezMiguel MJ: Interleukin-I gene polymorphisms and gastric cancer risk in a high-risk Italian population. Am J Gastroenterol 2005, I00:194I-1948.

19. Palli D, Saieva C, Gemma S, Masala G, Gomez-Miguel MJ, Luzzi I, D'Errico M, Matullo G, Ozzola G, Manetti R, Nesi G, Sera F, Zanna I, Dogliotti E, Testai E: GSTTI and GSTMI gene polymorphisms and gastric cancer in a high-risk italian population. Int J Cancer 2005, I I 5:284-289.

20. Ottini L, D'Amico C, Noviello C, Lauro S, Lalle M, Fornarini G, Colantuoni OA, Pizzi C, Cortesi E, Carlini S, Guadagni F, Bianco AR, Frati L, Contegiacomo A, Mariani-Costantini R: BRCAI and BRCA2 mutations in central and southern Italian patients. Breast Cancer Res 2000, 2:307-310.

21. Orwoll E, Lambert LC, Marshall LM, Phipps K, Blank J, Barrett-Connor E, Cauley J, Ensrud K, Cummings S: Testosterone and estradiol among older men. J Clin Endocrinol Metab 2006, 91:1336-I344

22. Zhoucun A, Zhang S, Yang Y, Ma Y, Zhang W, Lin L: The common variant $\mathrm{N} 372 \mathrm{H}$ in BRCA2 gene may be associated with idiopathic male infertility with azoospermia or severe oligozoospermia. Eur J Obstet Gynecol Reprod Biol 2006, 1 24:6I-64.

23. Palli D, Masala G, Mariani-Costantini R, Zanna I, Saieva C, Sera F, Decarli A, Ottini L: A gene-environment interaction between occupation and BRCAI/BRCA2 mutations in male breast cancer? Eur J Cancer 2004, 40:2474-2479.

24. Teare MD, Cox A, Shorto J, Anderson C, Bishop DT, Cannings C: Heterozygote excess is repeatedly observed in females at the BRCA2 locus N372H. J Med Genet 2004, 4I:523-528.

\section{Pre-publication history}

The pre-publication history for this paper can be accessed here:

http://www.biomedcentral.com/1471-2407/7/170/pre

pub
Publish with Bio Med Central and every scientist can read your work free of charge

"BioMed Central will be the most significant development for disseminating the results of biomedical research in our lifetime. "

Sir Paul Nurse, Cancer Research UK

Your research papers will be:

- available free of charge to the entire biomedical community

- peer reviewed and published immediately upon acceptance

- cited in PubMed and archived on PubMed Central

- yours - you keep the copyright
BioMedcentral 